\title{
Increased heme-oxygenase 1 expression in mesenchymal stem cell-derived adipocytes decreases differentiation and lipid accumulation via upregulation of the canonical Wnt signaling cascade
}

Luca Vanella ${ }^{1,2+}$, Komal Sodhi ${ }^{1 \dagger}$, Dong Hyun Kim ${ }^{1}$, Nitin Puri ${ }^{3}$, Mani Maheshwari ${ }^{1}$, Terry D Hinds $\mathrm{Jr}^{3}$, Lars Bellner ${ }^{4}$, Dov Goldstein ${ }^{5}$, Stephen J Peterson ${ }^{4}$, Joseph I Shapiro ${ }^{1}$ and Nader G Abraham ${ }^{{ }^{*}}$

\begin{abstract}
Introduction: Heme oxygenase (HO), a major cytoprotective enzyme, attenuates oxidative stress and obesity. The canonical Wnt signaling cascade plays a pivotal role in the regulation of adipogenesis. The present study examined the interplay between $\mathrm{HO}-1$ and the Wnt canonical pathway in the modulation of adipogenesis in mesenchymal stem cell (MSC)-derived adipocytes.
\end{abstract}

Methods: To verify the role of HO-1 in generating small healthy adipocytes, cobalt protoporphyrin (CoPP), inducer of HO-1, was used during adipocyte differentiation. Lipid accumulation was measured by Oil red $\mathrm{O}$ staining and lipid droplet size was measured by BODIPY staining.

Results: During adipogenesis in vitro, differentiating pre-adipocytes display transient increases in the expression of genes involved in canonical Wht signaling cascade. Increased levels of HO-1 expression and $\mathrm{HO}$ activity resulted in elevated levels of $\beta$-catenin, pGSK3 $\beta$, Wnt10b, Pref-1, and shh along with increased levels of adiponectin $(P<0.05)$. In addition, induction of HO-1 resulted in a reduction in C/EBP $\alpha$, PPAR $\gamma$, Peg-1/Mest, aP2, CD36 expression and lipid accumulation $(P<0.05)$. Suppression of HO-1 gene by siRNA decreased Wnt10b, pGSK3 $\beta$ and $\beta$-catenin expression, and increased lipid accumulation. The canonical Wnt responsive genes, IL-8 and SFRP1, were upregulated by COPP and their expression was decreased by the concurrent administration of tin mesoporphyrin (SnMP), an inhibitor of $\mathrm{HO}$ activity. Furthermore, knockdown of Wnt10b gene expression by using siRNA showed increased lipid accumulation, and this effect was not decreased by concurrent treatment with CoPP. Also our results show that blocking the Wnt 10b antagonist, Dickkopf 1 (Dkk-1), by siRNA decreased lipid accumulation and this effect was further enhanced by concurrent administration of CoPP.

Conclusions: This is the first study to demonstrate that HO-1 acts upstream of canonical Wnt signaling cascade and decreases lipogenesis and adipocyte differentiation suggesting that the HO-1 mediated increase in Wnt10b can modulate the adipocyte phenotype by regulating the transcriptional factors that play a role in adipogenesis. This is evidenced by a decrease in lipid accumulation and inflammatory cytokine levels, increased adiponectin levels and elevation of the expression of genes of the canonical Wnt signaling cascade.

\footnotetext{
* Correspondence: abrahamn@marshall.edu

+ Contributed equally

'Joan C. Edwards School of Medicine, Marshall University, 1600 Medical

Center Drive, Huntington, WV, 25701-3655, USA

Full list of author information is available at the end of the article
} 


\section{Introduction}

Human bone marrow-derived mesenchymal stem cells (MSCs) are multipotent cells that have the potential to differentiate into a variety of cell types including adipocytes [1-5]. MSC-derived adipocyte differentiation and dysregulation of adipogenesis is implicated in the pathogenesis of diseases such as metabolic syndrome [4]. Enhanced adipogenesis with adipocyte hypertrophy is one of the leading causes of adipose tissue hypoxia, inflammation, and dysfunction [6]. Hence, the elucidation of the mechanisms that regulate commitment of MSCs towards adipogenic fate may offer a portal to the development of treatment for metabolic syndrome and its related vascular complications.

Adipogenesis begins with the commitment of MSCs to the adipocyte lineage, followed by terminal differentiation of pre-adipocytes to mature adipocytes [5,7]. Fat tissuederived adipocytes express several regulatory proteins such as Wnts and $\beta$-catenin, as well as Sonic hedgehog (Shh), which potentially works upstream of these known differentiation factors to induce osteogenesis in MSCs [8]. Wnts regulate gene expression through either the canonical ( $\beta$-catenin-dependent) or the non-canonical $(\beta$-catenin-independent) pathway $[9,10]$. The canonical Wnt signaling pathway controls cell proliferation, cell survival and cell fate. Wnt ligands are secreted glycoproteins that function in a paracrine and autocrine manner. Among the Wnt ligands identified, Wnt10b has been shown to be a crucial factor in the activation of the canonical pathway and inhibition of adipogenesis $[11,12]$. Adipose tissue-specific transgenic over-expression of Wnt10b leads to a significant decrease in adiposity and resistance to a high-fat diet in mice [13]. The canonical Wnt pathway relies on stabilization of $\beta$ catenin. The Wnt $/ \beta$ catenin signaling pathway affects cellular functions by regulating both $\beta$ catenin levels and subcellular localization [14].

An increase in Wnt $/ \beta$-catenin signaling inhibits the adipogenic transcription factor CCAAT/enhancer binding protein $(\mathrm{C} / \mathrm{EBP} \alpha)$ and the peroxisome proliferator activator receptor (PPAR $\gamma)$ [11,15-17]. Adipocyte differentiation is an ordered multistep process requiring the sequential activation of several groups of transcription factors, including CCAAT/enhancer-binding protein (C/EBP $\alpha)$ gene family and peroxisome proliferator activated receptor- $\gamma($ PPAR $-\gamma)[1,18]$. C/EBP $\alpha$ and PPAR $\gamma$ are involved in the growth arrest that is required for adipocyte differentiation. Pre-adipocyte factor-1 (Pref-1) belongs to the Notch family of epidermal growth factor-like repeat-containing proteins and has been shown to participate in maintaining pre-adipose phenotype [19]. Pref- 1 is an inhibitor of adipocyte differentiation, hence a decrease in Pref- 1 expression is observed during differentiation of adipocytes [20]. The paternally expressed 1 (Peg-1)/Mesoderm-specific transcript (Mest) [21], when upregulated, results in the enlargement of adipocytes during adipose tissue expansion [22]. On accumulation of triglycerides, the levels of Peg-1/ Mest [22] are increased with a concomitant signal to preadipocytes to enlarge in order to accommodate more triglycerides. Adipocyte enlargement is associated with an increase in the levels of TNF $\alpha$, IL-1, IL-6 and increased insulin resistance [23-26]. Hedgehog signaling exerts its pleiotropic effects through regulation of the cell cycle, direction of cell differentiation, and alteration of cell survival [27]. Conversely, Shh signaling represses adipogenic differentiation in pre-adipocytes [28].

Heme oxygenase-1 (HO-1) is a stress response gene critical for bone marrow cell differentiation [29-31]. A porphyrin structure within cyanocobalamine enables it to induce $H O-1$ gene expression by facilitating its binding to the porphyrin binding domain of the HO-1 gene. Induction of HO-1 enhances cell survival and moderates diabetes and obesity [32]. Induction of $\mathrm{HO}-1$ gene expression in vivo and in cell culture results in an increase in pre-adipocytes, a reduction in the number of enlarged adipocytes, and an increase in small adipocyte and adiponectin levels [33]. A decrease in HO-1 expression results in increased insulin resistance and adiposity in Zucker rats and obese mice [34]. Additionally, induction of HO-1 in adipocyte cell culture is associated with increased adiponectin levels and decreased pro-inflammatory cytokines, TNF $\alpha$ and IL-6 $[35,36]$.

The goal of this study was to elucidate the role of $\mathrm{HO}-1$ gene expression on adipogenesis and clarify the role of Wnt10b and its dependent genes in this process. Induction of HO-1 gene expression and $\mathrm{HO}$ activity decreased lipid deposition and inflammatory cytokine levels, increased adiponectin levels and elevated the expression of genes of the canonical Wnt signaling cascade. These novel findings demonstrate that increased levels of HO-1 appear crucial in modulating the phenotype of adipocytes to express canonical downstream signaling proteins.

\section{Materials and methods}

Differentiation of human bone marrow-derived MSCs into adipocytes

Frozen bone marrow mononuclear cells were purchased from Allcells (Allcells, Emeryville, CA, USA). After thawing, mononuclear cells were resuspended in an $\alpha$-minimal essential medium ( $\alpha$-MEM, Invitrogen, Carlsbad, CA, USA) supplemented with 10\% heat-inactivated FBS (Invitrogen) and $1 \%$ antibiotic/antimycotic solution (Invitrogen). The cells were plated at a density of 1 to $5 \times 10^{6}$ cells per $100-\mathrm{cm}^{2}$ dish. The cultures were maintained at $37^{\circ} \mathrm{C}$ in a $5 \% \mathrm{CO}_{2}$ incubator and the medium was changed after $48 \mathrm{~h}$ and every 3 to 4 days thereafter. When the MSCs were confluent, the cells were recovered by the addition of $0.25 \%$ trypsin/ethylenediaminetetraacetic acid (EDTA) (Invitrogen). MSCs (passage 2 to 3 ) were plated in a 
$75-\mathrm{cm}^{2}$ flask at a density of 1 to $2 \times 10^{4}$ cells and cultured in $\alpha$-MEM with $10 \%$ FBS for 7 days. The medium was replaced with adipogenic medium, and the cells were cultured for an additional 14 days as described previously [37]. Human MSCs, passage 3, were cultured in the presence of the HO-1 inducer cobalt protoporphyrin (CoPP) $(5 \mu \mathrm{M})$ and with the $\mathrm{HO}$ activity inhibitor tin $\left(\mathrm{Sn}^{4+}\right)$-mesoporphyrin (SnMP) $(5 \mu \mathrm{M})$, which were administered every 2 days.

\section{HO activity measurement}

Heme oxygenase activity was measured in hMSCs by carbon monoxide $(\mathrm{CO})$ production in cellular homogenates. Briefly, hMSCs were homogenized in Sucrose (255 mM)Tris hydrochloride $(20 \mathrm{mM}$ ) buffer ( $\mathrm{pH} 7.4)$ with NP-40 $(1 \% \mathrm{w} / \mathrm{v})$, EDTA $(1 \mathrm{mM})$, phenylmethylsulfonyl fluoride (PMSF) (1 mM) and mammalian protease inhibitor cocktail $(5 \% \mathrm{v} / \mathrm{v})$. After homogenization, samples were centrifuged, at $6000 \times \mathrm{g}$ for 30 minutes at $4{ }^{\circ} \mathrm{C}$, and the supernatant collected for measurement of $\mathrm{HO}$ activity; $100 \mu \mathrm{g}$ protein/sample was incubated, in gas-sealed vials, in Sucrose-Tris buffer along with nicotinamide adenine dinucleotide phosphate-oxidase (NADPH) $(1 \mathrm{mM})$ and excess heme $(40 \mu \mathrm{M})$, in both the absence and the presence of SnMP $(2 \mu \mathrm{M})$. Samples were incubated in a water bath, in the absence of light, at $37^{\circ} \mathrm{C}$ for $60 \mathrm{~min}$ utes, after which, the $\mathrm{HO}$ reaction was stopped by placing the samples in ice. $\mathrm{CO}$ generation was quantitated in the headspace using gas chromatography/mass spectrometry (GC/MS), as previously described [38], using $\mathrm{C}^{13} \mathrm{O}^{16}$ as an internal standard. Results are expressed as HO-dependent $\mathrm{CO}$ generation by subtracting the amount of $\mathrm{CO}$ in the presence of SnMP. CO generated is expressed as pmoles/mg protein/hour.

\section{Effect of CoPP on adipogenesis}

To measure the effect of increased HO-1 expression on MSC-derived adipocyte differentiation, cells were treated with $0.5,1.0,2.0,5.0$, and $10.0 \mu \mathrm{M}$ of CoPP every 4 days. After 14 days, cells were stained with Oil Red O solution.

\section{Oil Red 0 staining}

Staining was performed using $0.21 \%$ Oil Red O in $100 \%$ isopropanol (Sigma-Aldrich, St. Louis, MO, USA). Briefly, adipocytes were fixed in $10 \%$ formaldehyde, stained with Oil Red O for 10 minutes, rinsed with 60\% isopropanol (Sigma-Aldrich), and the Oil Red O eluted by adding $100 \%$ isopropanol for 10 minutes and the optical density (OD) measured at $490 \mathrm{~nm}$, for $0.5 \mathrm{sec}$ reading.

\section{Measurement of lipid droplet size}

After induction of adipogenesis, lipid droplets were stained with $2 \mu \mathrm{M}$ boron-dipyrromethene (BODIPY) 493/503 (Molecular Probes, Eugene, OR, USA) [39]. Cell size was measured using an ImagePro Analyzer (MediaCybernetics, Inc., Bethesda, MD, USA). The classification of the size of lipid droplets was based on size by area (pixels).

\section{Cell viability test by lactic dehydrogenate assay (LDH)}

We followed the manufacturer's protocol (LDH Assay kit, Cayman, Ann Arbor, MI, USA). Briefly, hMSC and adipocytes at day 14 were plated in 96-well plates for 1 day. Next day, cell layers were washed twice with PBS, and then cells were treated with various concentrations of CoPP $(0$ to $10 \mu \mathrm{M})$. After incubation for $24 \mathrm{~h}$, and addition of $100 \mu \mathrm{l}$ of reaction mixture to each well, cells were incubated for 4 hours at $37^{\circ} \mathrm{C}$ and $5 \% \mathrm{CO}_{2}$ in a humidified incubator. Absorbance was measured in the 96-well microplate using a microplate reader at $490 \mathrm{~nm}$ with $650 \mathrm{~nm}$ as the reference wavelength, and the percentage of LDH release for each sample was normalized according to the absorbance reading from samples treated with $0.5 \%$ Triton X-100. All analyses were replicated eight times.

\section{Cytokine array and adiponectin}

TNF $\alpha$ and adiponectin (high molecular weight, HMW), were measured as previously described $[25,40]$ by Cytokine SearchLight Infrared arrays (Pierce Biotechnology, Inc., Woburn, MA, USA).

\section{HO-1 siRNA transfection}

Cells were treated with three different predesigned siRNAs of the HO-1 gene (SASI_Hs01_00035068, SASI_Hs01_00035065 and SASI_Hs01_00035067 from Sigma-Aldrich, St. Louis, MO, USA). According to the manufacturer's protocol, adipogenic media containing siRNA using NTER (Sigma-Aldrich) was replaced every $48 \mathrm{~h}$. Briefly, a nanoparticle solution was incubated with $10 \mathrm{nM}$ siRNA. After 20 minutes cells were treated with siRNA solution during adipogenesis, which was halted after 10 days.

\section{Measurement of MSC-derived adipocyte signaling molecules}

Cells were maintained at $-80^{\circ} \mathrm{C}$ until required for assay. Frozen cells were pulverized and placed in a homogenization buffer (10 mM phosphate buffer, $250 \mathrm{mM}$ sucrose, $1 \mathrm{mM}$ EDTA, $0.1 \mathrm{mM}$ PMSF and $0.1 \%$ tergitol, $\mathrm{pH}$ 7.5). Homogenates were centrifuged at $27,000 \times \mathrm{g}$ for $10 \mathrm{~min}-$ utes at $4^{\circ} \mathrm{C}$. The supernatant was isolated and protein levels were assayed (Bradford Method). The supernatant was used for measurement of HO-1, Wnt10b, $\beta$-catenin, Pref-1, C/EBP $\alpha$, Peg-1/Mest, pGSK3 $\beta$, shh, PPAR $\gamma$ and $\beta$-actin levels as described previously [25,41]. $\beta$-Actin was used to ensure adequate sample loading for all western blots. 


\section{Quantitative real-time PCR analysis}

Total RNA was extracted from differentiated human mesenchymal stem cells using 5-Prime PerfectPure RNA Tissue Kit (Fisher Scientific Company, LLC, Wilmington, DE, USA). Total RNA was read on a NanoDrop 2000 spectrophotometer (Thermo Fisher Scientific) and cDNA was synthesized using High Capacity cDNA ReverseTranscription Kit (Life Technologies, Grand Island, NY, USA). PCR amplification of the cDNA was performed by quantitative real-time PCR using TrueAmp SYBR Green qPCR SuperMix (Smart Bioscience, Philadelphia, USA). The thermocycling of IL- 8 and Secreted frizzled-related protein 1 (SFRP1) protocol consisted of 5 minutes at $95^{\circ} \mathrm{C}, 40$ cycles of $15 \mathrm{sec}$ at $95^{\circ} \mathrm{C}$, and $30 \mathrm{sec}$ at $60^{\circ} \mathrm{C}$, and finished with a melting curve ranging from 60 to $95^{\circ} \mathrm{C}$ to allow distinction of specific products. Normalization was performed in separate reactions with primers to $18 \mathrm{~S}$ mRNA (TTC GAACGTCTGCCCTATCAA and ATGG TAGGCACGGCGACTA).

\section{Statistical analyses}

Statistical significance $(P<0.05)$ of differences between experimental groups was determined by the Fisher method for analysis of multiple comparisons. For comparison between treatment groups, the null hypothesis was tested by either single-factor analysis of variance (ANOVA) for multiple groups, or the unpaired $t$-test for two groups, and the data are presented as mean \pm standard error (SE).

\section{Results}

The effect of adipogenesis on $\mathrm{HO}-1$ expression

The temporal sequence of $\mathrm{HO}-1$ expression was determined over a 14-day period in MSC-derived adipocytes. The basal levels of HO-1 expression increased during MSC adipogenic culture growth and peaked at day 3 (Figure 1B). This was followed by gradual decrease in HO1 expression, while lipid droplet area gradually increased over a period of 14 days (Figure 1A).

\section{The effect of CoPP on cell viability during adipogenesis by LDH assay}

Detection of cell membrane integrity is a rapid and simple approach to determine cell viability by measuring cellular LDH leakage in damaging cells. Our results showed that CoPP treatment in MSCs and adipocytes at day 14 have no cytotoxic effects at concentrations up to $5 \mu \mathrm{M}$ (Figure $1 C)$. However, MSCs and adipocytes showed significant toxicity at a $10 \mu \mathrm{M}$ concentration of $\mathrm{CoPP}(P<0.05)$.

The effect of CoPP on HO-1 expression, HO activity and cytokine levels during adipogenesis

We examined the effect of CoPP on lipid accumulation after 14 days, using standard culture conditions by measuring Oil Red O-stained lipid droplet area (Figure 2A). The level of cells with Oil Red O-stained lipid droplets decreased as CoPP concentration increased. CoPP decreased lipid accumulation in a concentration-dependent manner. Oil Red O staining was barely detectable at the highest concentration of CoPP $(10 \mu \mathrm{M})$, although untreated MSC-derived adipocyte progenitor cells were loaded with lipid droplets (control). Quantification of Oil Red O-stained cells showed an increase in the number of adipocytes in the absence of CoPP $(77,093 \pm 943$ pixels $)$ compared with the presence of CoPP $(54,376 \pm 5,366$ and $3,526 \pm 368$ pixels) at 1 and $10 \mu \mathrm{M}$, respectively. The expression of HO-1 in the presence of CoPP increased in a dose-dependent manner (Figure 2B), which was consistent with our results showing decreased lipogenesis with increased concentrations of CoPP (Figure 2A). HO activity, as measured by $\mathrm{CO}$ release, was increased in the presence of CoPP compared to the control (Figure 2C; $P<0.05)$. HO activity increased reaching a maximum $(P<0.05)$ at day 10 and remained elevated. This was in contrast to the control where $\mathrm{HO}$ activity remained at the same level as day 0. One possible explanation of this discrepancy between $\mathrm{HO}-1$ expression and $\mathrm{HO}$ activity could be differential effects of progressing adipogenesis on $\mathrm{HO}-1$ expression and activity. Other investigators $[42,43]$ have reported redox imbalances during the process of adipogenesis. We have previously shown that oxidative stress can induce $\mathrm{HO}$ expression while suppressing $\mathrm{HO}$ activity [44] (Figure 2C).

Adipose cell enlargement is associated with increased secretion of cytokines, which impairs the differentiation of pre-adipocytes and reduces adiponectin secretion. We examined the levels of TNF $\alpha$ in the conditioned media of CoPP-treated MSC-derived adipocytes, and found that TNF $\alpha$ levels were significantly decreased (Figure 2D; $P<$ 0.001 ) at day 14. In contrast, CoPP increased adiponectin levels were increased subsequent to CoPP treatment when compared to controls at day $14(P<0.05$; Figure $2 \mathrm{E})$.

\section{Effect of CoPP and SnMP on adipogenesis and} distribution of lipid droplet size, stained by BODIPY

After 14 days, the number of lipid droplets stained with Oil Red O was lower after CoPP treatment when compared to control $(P<0.05$; Figure $3 \mathrm{~A}-\mathrm{B})$. In contrast, $\mathrm{HO}$ activity inhibitor, SnMP treatment, resulted in higher levels of Oil Red O staining when compared to control (Figure 3A-B). To confirm that increased levels of HO-1 resulted in decreased lipid accumulation, we stained lipid droplets with BODIPY/4',6-diamidino-2-phenylindole (DAPI) (Figure 3C). CoPP treatment decreased the number of very large lipid droplets $(P<0.05)$ and increased the number of small lipid droplets when compared with control (Figure 3D). In contrast, SnMP significantly increased the number of large lipid droplets $(P<0.05)$ 

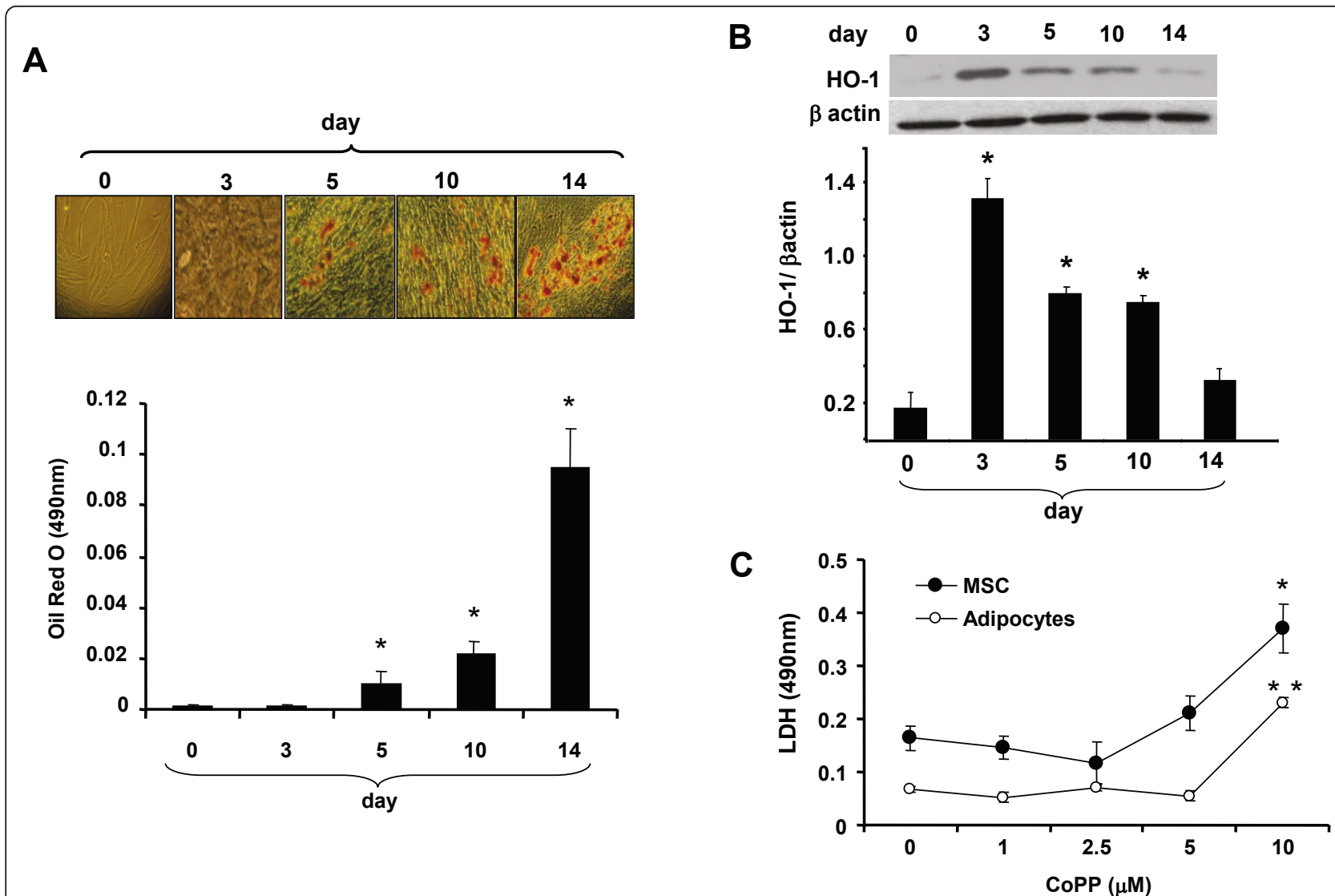

Figure 1 Expression of heme oxygenase-1 (HO-1), with time, on adipogenesis. (A) Pictures of lipid droplets of a representative experiment at days $3,5,10$, and 14. Adipogenesis was measured as the relative absorbance of Oil Red $\mathrm{O}$ as described in Materials and methods (mean \pm $\mathrm{SD}$, ${ }^{*} P<0.05$ vs control). (B) Western blot of HO-1 and actin in mesenchymal stem cell (MSC)-derived adipocytes from day 0 to day 14 . Representative immunoblots and densitometry analysis are shown. Data are expressed as means \pm SD; $n=4$; ${ }^{*} P<0.05$. (C) Lactic dehydrogenate $(\mathrm{LDH})$ assay done to study the cytotoxicity at increasing concentrations of cobalt-protoporphyrin IX (CoPP). Data are expressed as means \pm SD; $n=8,{ }^{*} P<0.05$ vs MSC control, ${ }^{*} P<0.05$ vs adipocytes control.

and decreased the number of small lipid droplets, compared with either culture treated with CoPP or control, indicating that this effect is mediated by increased $\mathrm{HO}$ activity (Figure 3D). The results were quantified and are shown in Figure 3E.

\section{Effect of CoPP and SnMP on CD36 expression}

CD36, a fatty acid translocase, which mediates the transfer of fatty acids (FAs) into the cell [45], was measured in MSCs and MSC-derived adipocytes treated with either CoPP $(5 \mu \mathrm{M})$ or SnMP $(5 \mu \mathrm{M})$. Cells were treated with adipogenic media and collected after 14 days. As seen in Figure 4A, during lipogenesis CoPP decreased CD36 expression $(25.21 \pm 1.67 \%)$ compared to control (44.29 \pm 4.33\%), while SnMP increased CD36 expression (52.83 \pm $3.12 \%)$. The results are quantified in Figure $4 \mathrm{~B}$ and show that CoPP decreased CD36 levels $(P<0.05)$ compared to control indicating decreased fatty acid uptake in adipocytes by upregulation of HO-1. As expected, SnMP restored CD36 levels to those seen in control, suggesting that increased HO-1 expression and activity has anti-adipogenic response on adipocytes.

\section{Effect of siRNA HO-1 on adipogenesis}

Upregulation of HO-1 by CoPP decreased lipid accumulation, which was measured as the relative absorbance of Oil Red O. To selectively assess the role of $\mathrm{HO}-1$ on adiposity, HO-1 siRNA was added to the cell culture. Lipid accumulation was increased after HO-1 siRNA treatment as compared to MSCs treated with CoPP (Figure 5A; $P<0.05$ ). Densitometry analysis showed that CoPP treatment increased $\mathrm{HO}-1$ expression in MSC-derived adipocytes compared to the control, and this effect was reversed by siRNA HO-1 (Figure 5B; $P<0.01$ ). The protein expression of Shh increased with CoPP treatment and was reversed by siRNA HO-1 (Figure 5 C). Pref- 1 , an excellent marker for pre-adipocytes, which is extinguished during adipocyte differentiation [19], was increased by CoPP treatment and was decreased by siRNA HO-1 (Figure 5G). Upregulation of HO-1 by CoPP treatment decreased levels of the 


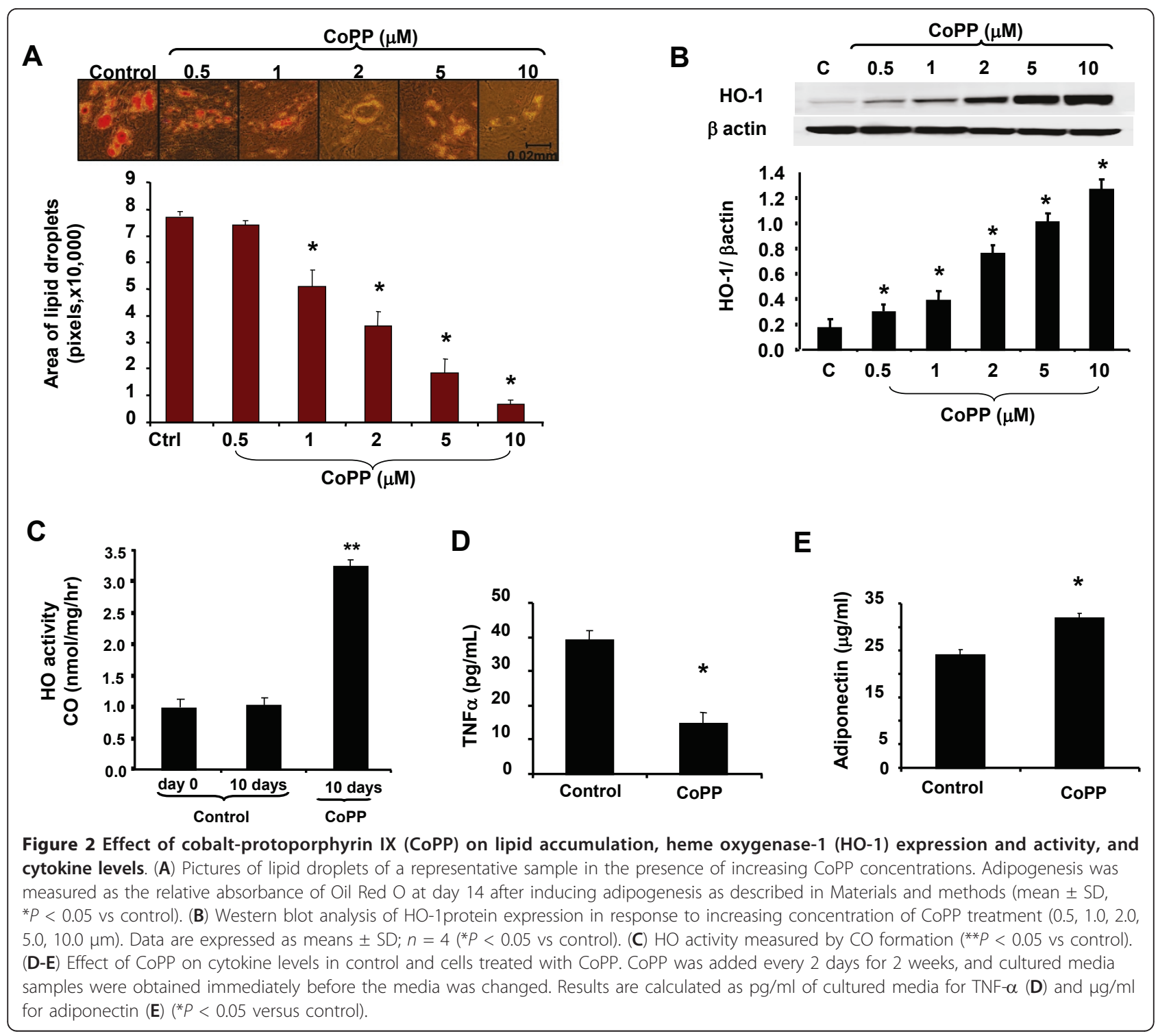

adipogenic markers Peg-1/Mest, aP2, C/EBP $\alpha$ and PPAR $\gamma$ in MSC-derived adipocytes, and this effect was reversed by transduction with $\mathrm{HO}-1$ siRNA (Figure 5D, E, E, G and $5 \mathrm{H}$ respectively; $P<0.02$ ).

\section{Effect of siRNA HO-1 on canonical Wnt signaling and Wnt-responsive genes}

Upregulation of $\mathrm{HO}-1$ by CoPP treatment increased protein expression of the canonical Wnt signaling cascade, Wnt10b, pGSK3 $\beta$ and $\beta$-catenin in MSC-derived adipocytes as compared to the control. To selectively assess the role of HO-1 on adiposity, HO-1 siRNA was added to cell culture with a resultant decrease in Wnt10b, pGSK3 $\beta$ and $\beta$-catenin levels (Figure 6A, B and $6 \mathrm{C}$ respectively; $P<0.05)$. Canonical Wnt signaling cascade is known to activate IL-8 and SFRP1 [46]. The levels of these Wnt responsive genes, IL-8 and SFRP1, were increased by CoPP treatment and these effects were reversed by concurrent treatment with SnMP (Figure 6D and E respectively; $P<0.05$ ).

Effect of CoPP on canonical Wnt signaling cascade during adipogenesis

Our results show Oil Red $\mathrm{O}$ staining was increased after siRNA HO-1 treatment compared to MSCs treated with CoPP (Figure 7A). To elucidate the role of Wnt10b in the regulation of adipogenesis in MSC-derived adipocytes, we measured the effect of suppression of Wnt10b on adipogenesis, using siRNA. The addition of siRNA Wnt10b increased lipid formation compared to the vehicle $(P<$ $0.05)$, and this effect was not significantly altered by concurrent administration of CoPP, suggesting a possible 


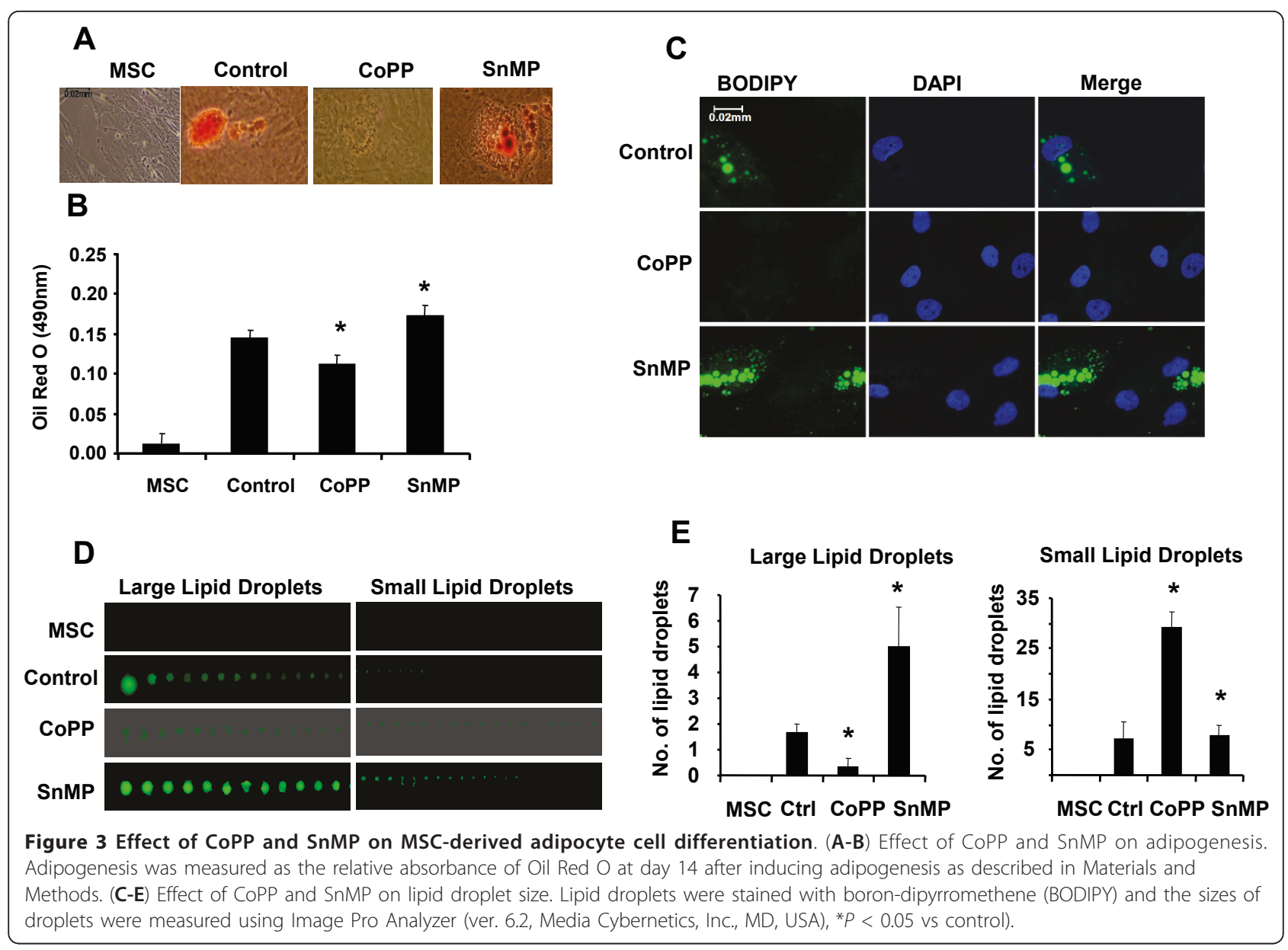

interaction between $\mathrm{HO}-1$ and the Wnt10b pathway. Wnt antagonist, Dickkopf 1 (Dkk1), is secreted by human preadipocytes and promotes adipogenesis [47]. Further our results show that knockdown of Wnt antagonist Dkk1 by siRNA showed significant reduction in lipid accumulation compared to siRNA Wnt10b, and more importantly, administration of CoPP further significantly deceased lipogenesis $(P<0.05$; Figure $7 \mathrm{~A})$.

The protein expression of $\beta$-catenin and phosphorylated glycogen synthase kinase (GSK3) $\beta$ was measured to study the effect of Wnt10b inhibition by using siRNA (Figure 7B and 7C respectively). Our results showed decreased expression of $\beta$-catenin and pGSK3 $\beta$ when MSCs were treated with Wnt10b siRNA compared to the control $(P<0.05)$ and this effect was not reversed by concurrent treatment with CoPP. We next determined whether inhibition of Dkk1 using siRNA affected these adipogenic markers. Our results further showed that $\beta$-catenin and pGSK3 $\beta$ levels were increased compared to the MSCs treated with siRNA Wnt10b. More importantly, concurrent administration of CoPP significantly increased the gene expression of $\beta$-catenin and
pGSK3 $\beta(P<0.05)$ compared to the cells treated with siRNA Dkk1.

\section{Discussion}

This study demonstrates that the effects of HO-1 induction in a cell-based model of adipogenesis are dependent upon activation of the Wnt canonical signaling pathway. HO-1 induction has reduced body weight and adiposity $[25,48]$ and improved the metabolic profile in animal models of obesity $[24,49]$. It has also been shown that upregulation of HO-1 reduces adipogenesis in cell cultures [34]. We show here in a cell-based model of adipogenesis (MSCs) that HO-1 induction mediates the recruitment of the Wnt canonical cascade, and entails reduced lipid accumulation comprised of smaller healthier adipocytes, reduced inflammation and improved adipokine secretion.

Differentiation of pre-adipocytes into adipocytes is regulated by a balance of transcriptional factors that can both positively and negatively influence differentiation. This is reflected by the appearance of various early, intermediate and late mRNA/protein markers and triglyceride accumulation. Several reports describe an association 


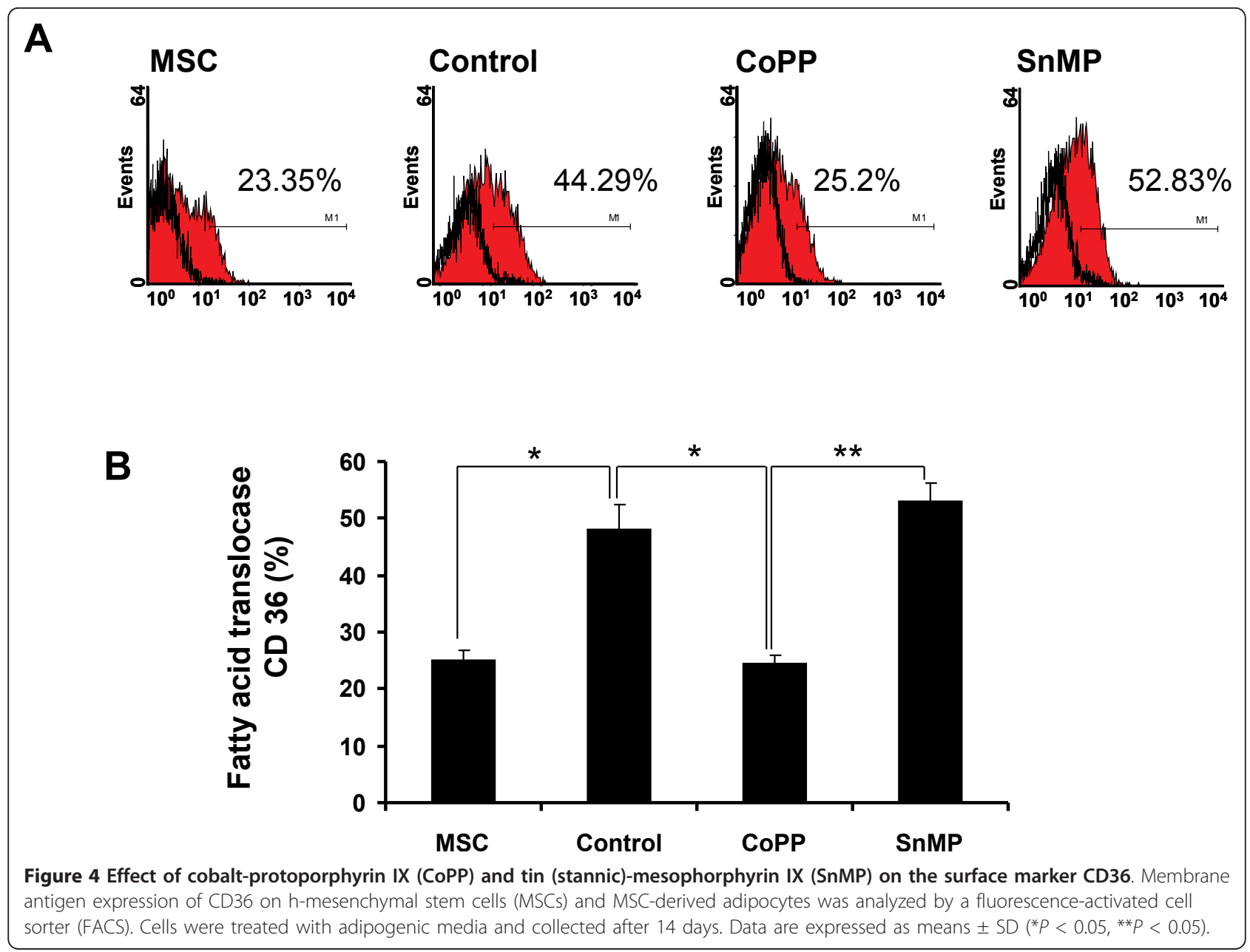

between adipogenesis and Wnt signaling in the regulation of adult tissue homeostasis and remodeling [50,51]. Wnt10b is an endogenous regulator of adipogenesis that maintains pre-adipocytes in an undifferentiated state and functions as an adipogenic switch. The activation of Wnt10b contributes to the inactivation/phosphorylation of GSK3 $\beta$ and consequently, elevated level of $\beta$-catenin; it is the molecular node of the canonical Wnt signaling pathway. When Wnt signaling is active, GSK3 is inhibited. Conversely, when Wnt signaling is suppressed, GSK3 phosphorylates $\beta$-catenin and targets it for ubiquitin-mediated degradation [11]. Our results describe a critical link between the anti-adipogenic effects of HO-1 and stimulation of the Wnt canonical pathway. Two lines of evidence characterize this relationship: First, HO-1 induction in CoPP-treated cells was accompanied by increased levels of Wnt10b and its associated signaling mediators, namely, phosphorylated GSK3 $\beta$ and $\beta$-catenin. The concurrent reduction in adipocyte size and lipid accumulation establishes a link between this phenotype, that is, HO-1 induction and Wnt signaling. Second,
siRNA-mediated downregulation/inhibition of Wnt10b prevented HO-1 from reducing adipocyte hypertrophy in MSCs. Further our results show that inhibition of Dkk1 by siRNA decreased lipogenesis, and this effect was further enhanced by concurrent administration of CoPP. These observations indicate that activation of the Wnt canonical pathway plays a role in the prevention of adipocyte hypertrophy and the promotion of smaller healthier adipocytes in MSCs undergoing HO-1 induction. The precise molecular mechanism linking HO-1 to activation of Wnt signaling is unclear. However, the restoration of the redox environment as a result of $\mathrm{HO}-1$ induction [37] could contribute to activation of Wnt signaling. In this regard, it should be noted that chronic oxidative stress has been shown to suppress the Wnt canonical pathway $[52,53]$ while enhancing lipid accumulation and hypertrophy in MSC-derived adipocytes. Furthermore, our studies show that upregulation of HO1and increased $\mathrm{HO}$ activity lead to increased levels of the Wnt-responsive genes, $I L-8$ and SFRP1, which was reversed by the HO-1 inhibitor, SnMP. Thus, these 


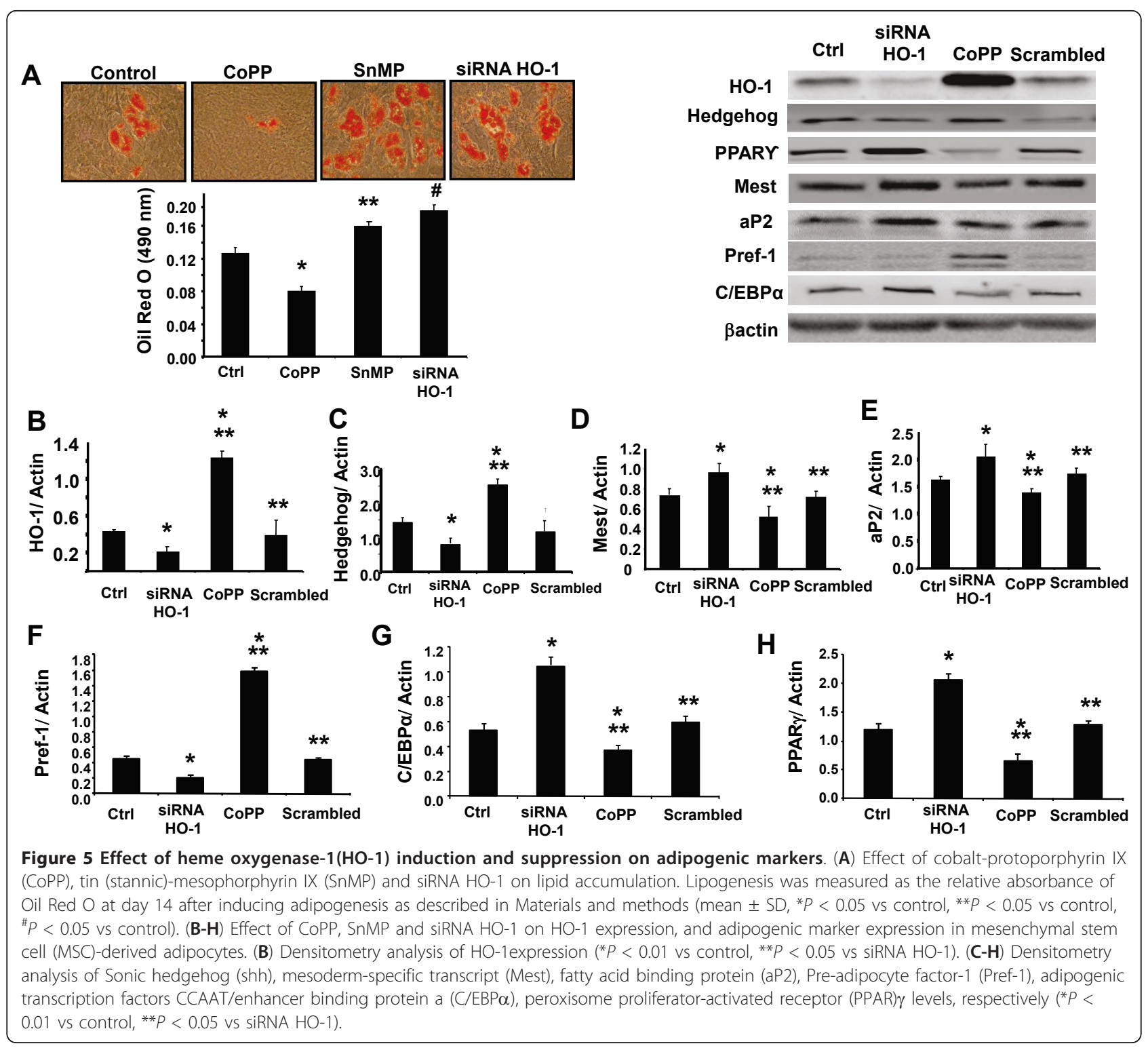

results substantiate our hypothesis that Wnt10b may be considered an HO-1 gene target that when increased, ultimately results in a reduction in adipocyte hypertrophy.

Activation of Wnt/ $\beta$-catenin signaling maintains preadipocytes in an undifferentiated state through inhibition of the adipogenic transcription factors, C/EBP $\alpha$ and PPAR $\gamma$ [15-17]. C/EBP $\alpha$ and PPAR $\gamma$ have been shown to activate adipocyte-specific genes and are involved in the growth arrest that is required for adipocyte differentiation. Our results show that the increased expression of HO-1 resulted in either maintaining pre-adipocytes in the undifferentiated state or slowed down this process, presumably through activation of Wnt/ $\beta$-catenin and inhibition of $\mathrm{C} /$ EBP $\alpha$ and PPAR $\gamma$ levels. Pref-1 has also been shown to participate in maintaining the pre-adipose phenotype. A decrease in Pref- 1 expression is observed during adipocyte differentiation. In adipose tissue, Pref- 1 is specifically expressed in pre-adipocytes but not in adipocytes and thus, is used as a pre-adipocyte marker [54]. In concordance with these observations, our results showed that upregulation of HO-1 increased Pref-1 expression, suggesting that $\mathrm{HO}-1$ decreased adipocyte differentiation. Pref- 1 prevents lipid accumulation and expression of adipocyte transcription factors such as PPAR $\gamma$ and C/EBP $\alpha$, as well as other late adipocyte markers, including FA synthase and FABP4/aP2 [54]. CD36 and $a P 2$ are PPAR $\gamma$ target genes and their mRNA levels were significantly increased during adipocyte differentiation, leading to 


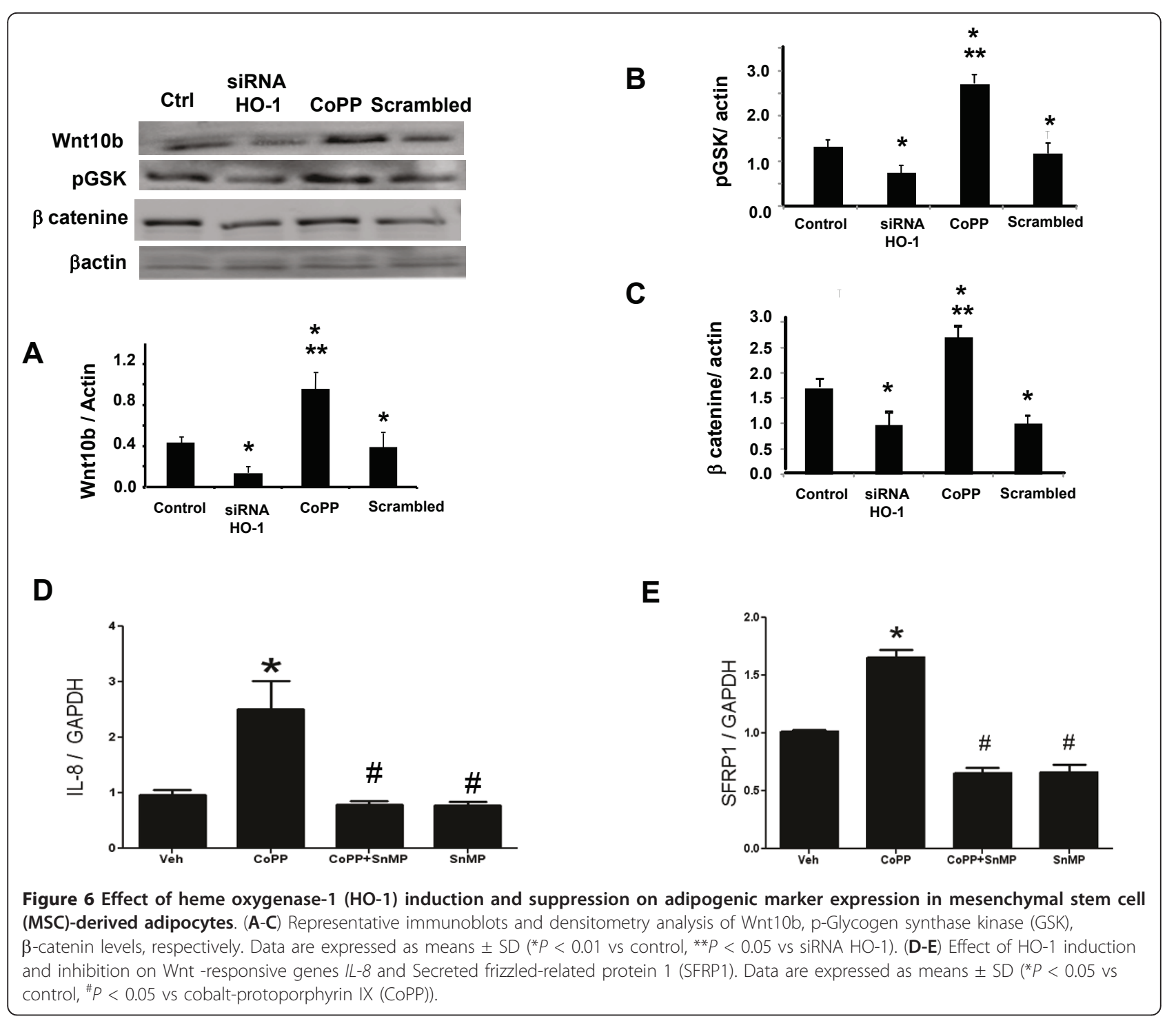

increased lipid storage and lipogenesis [55]. Lipid accumulation of avian adipocytes is mainly dependent upon the FA transmembrane uptake process mediated by membrane proteins, such as fatty acid translocase (FAT/CD36) [45]. Our studies show that increased HO-1 gene expression decreased aP2 and CD36 levels, suggesting that HO-1 mediated increase of Wnt10b could inhibit fatty acid accumulation and lipogenesis. Our study also showed that upregulation of $\mathrm{HO}-1$ is associated with increased adiponectin levels and decreased inflammatory cytokine, TNF $\alpha$. Increased pro-inflammatory and reduced anti-inflammatory cytokines reflect the functional consequences of upregulation of HO-1 in MSC-derived adipocytes [34]. Smaller adipocytes are considered to be healthy, insulin-sensitive adipocytes that are capable of producing adiponectin [48]. In light of this evidence, elevation of adiponectin along with suppression of TNF $\alpha$ synthesis by adipocytes cultured in the presence of $\mathrm{HO}-1$ induction complements the effect of the latter on adipocyte size. Together, these findings implicate the role of $\mathrm{HO}-1-\mathrm{Wnt}$ signaling in bringing about reduced lipid accumulation and improved adipocyte function in MSC-derived adipocytes. Wnts, $\beta$-catenin and Shh, are essential to regulate the conversion of pre-adipocytes to adipocytes $[16,47]$. In this regard, we also examined Shh, which potentially works upstream of these known differentiation factors to reduce adipogenesis [8,27]. Upregulation of HO-1 increased Shh protein expression, which was reversed by siRNA of $\mathrm{HO}-1$, confirming its role in decreasing adipocyte hypertrophy.

Our results show that the increase in Wnt10b in parallel with the increase in $H O-1$ gene expression by CoPP was associated with a significant reduction in levels of 


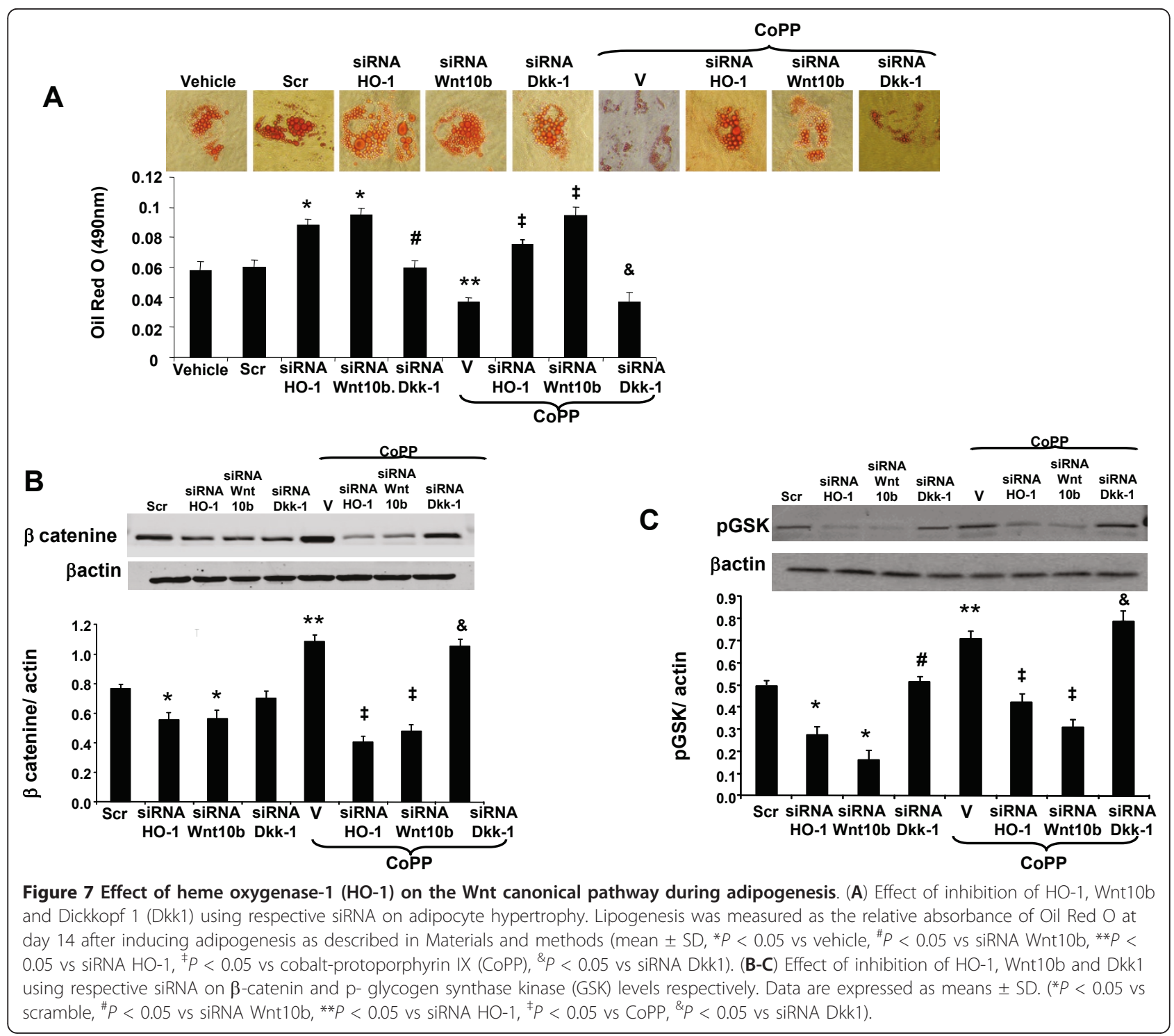

Peg-1/Mest. A decrease in Peg-1/Mest is beneficial in the control of obesity, since upregulation of Peg-1/Mest occurs in obese adipose tissue in several models of obesity $[21,56]$. Our data demonstrate that the induction of $\mathrm{HO}-1$ was effective in suppressing adipocyte differentiation, as evidenced by an increase in the canonical Wnt cascade and a decrease in Peg-1/Mest. These effects were reversed by blocking $H O-1$ gene expression by siRNA, further demonstrating that $\mathrm{HO}-1$ mediated-increase in Wnt10b, and decrease in Peg-1/Mest resulted in the maintenance of pre-adipocytes in their undifferentiated state with the slowing of the differentiation process. Taken together, these observations provide compelling evidence that $\mathrm{HO}-$ 1-mediated increase in Wnt signaling and its associated genes modulate adipogenesis.

\section{Conclusions}

In conclusion, as represented in the schematic (Figure 8), our novel study demonstrates that upregulation of $\mathrm{HO}-1$ gene expression and increased $\mathrm{HO}$ activity decreased adipocyte differentiation, with an associated increase in the number of small healthy lipid droplets via interplay of the Wnt signaling cascade. This is evident by the fact that increased HO-1 expression and $\mathrm{HO}$ activity decreased adipocyte hypertrophy, decreased TNF $\alpha$ levels, increased adiponectin level and increased expression of the genes central to the canonical Wnt signaling cascade. Thus, crosstalk between HO-1 and Wnt10b could be employed therapeutically to suppress adipogenesis, and therefore constitutes an attractive drug development target to combat obesity-associated metabolic complications. 


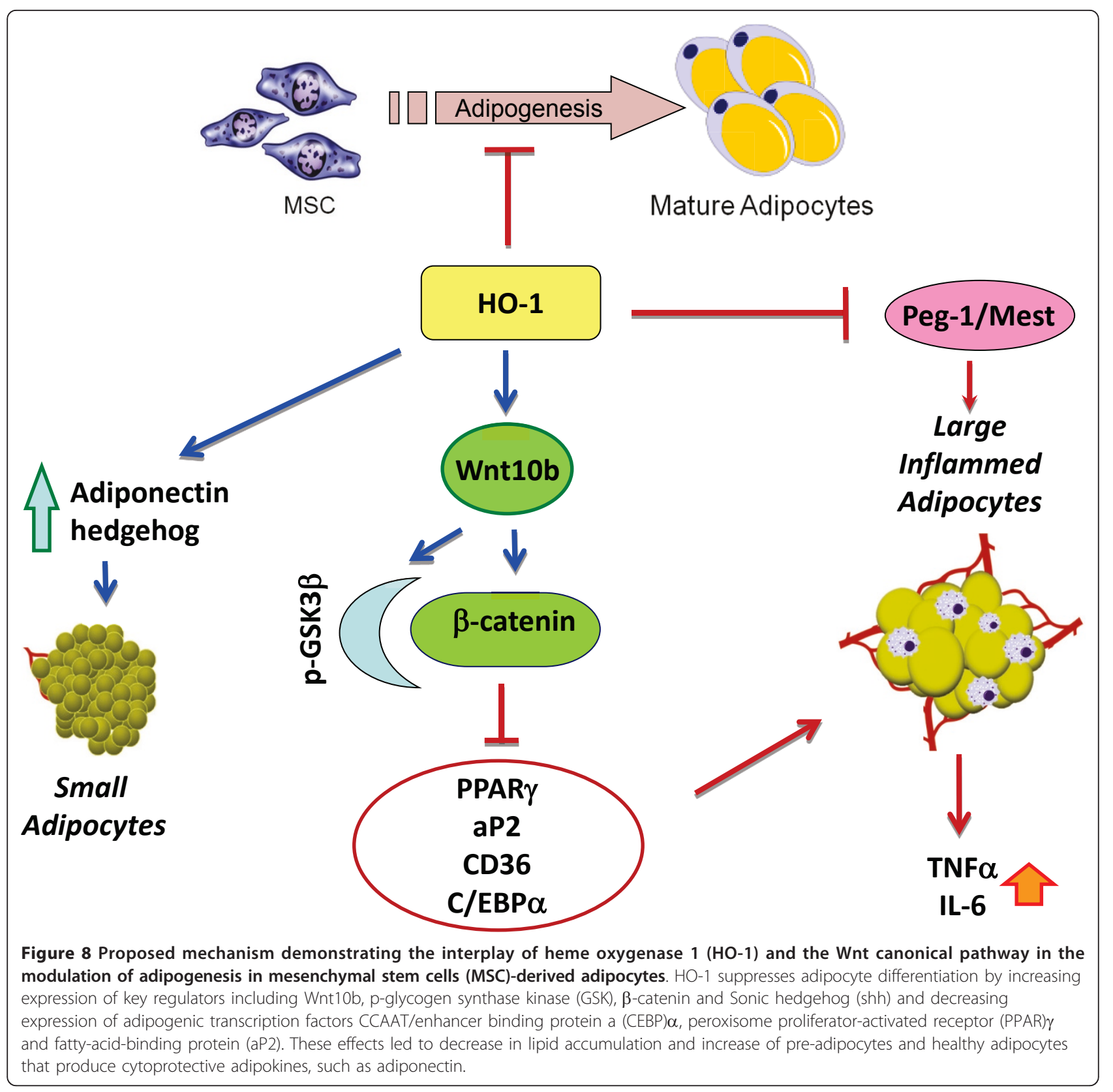

\section{Abbreviations}

aP2: fatty-acid-binding protein 4 (FABP4); BODIPY: boron-dipyrromethene; C/ EBP: adipogenic transcription factors CCAAT/enhancer binding protein a; CoPP: cobalt-protoporphyrin IX; DAPI: 4',6-diamidino-2-phenylindole; Dkk-1: Dickkopf 1; EDTA: ethylenediaminetetraacetic acid; EET: epoxyeicosatrienoic acids; FA: fatty acid; FAT/CD36: fatty acid translocase; FACS: fluorescenceactivated cell sorter; FBS: fetal bovine serum; GC/MS: gas chromatography/ mass spectrometry; GSK3 $\beta$ : glycogen synthase kinase $3 \beta$; HMW: high molecular weight; HO-1: heme oxygenase-1; IL: interleukin; LDH: lactic dehydrogenate; Mest: Mesoderm-specific transcript; MSC: mesenchymal stem cells; NADPH: nicotinamide adenine dinucleotide phosphate-oxidase; OD: optical density; PBS: phosphate-buffered saline; PCR: polymerase chain reaction; Peg 1: Paternally expressed 1; PMSF: phenylmethylsulfonyl fluoride; PPAR: peroxisome proliferator activator receptor; Pref-1; Pre-adipocyte factor1; SE: standard error; SFRP1: Secreted frizzled-related protein 1; Shh: Sonic hedgehog; SnMP: tin (stannic)-mesophorphyrin IX; TNF: tumor necrosis factor; Wnts: Wingless-type.

\section{Authors' contributions}

LV contributed equally to this work performing cell culture and $\mathrm{HO}$ levels and contributed in conception and design. KS contributed equally to this work, drafted the manuscript and repeated all work done by LV to confirm the results. D-HK performed Oil red stain and measurements. NP designed the siRNA, treatments, and harvested stem cells from culture. MM performed western blots for signaling. LB performed the cytotoxic assay. SJP was involved in design and input for the significance for clinical application. NGA, PI, designed, accumulated data, compared figures and examined various experiments. JIS revised the discussion and input to redraw several figures and scheme. All authors read and approved the final manuscript for publication. 


\section{Competing interests}

The authors declare that they have no competing interests.

\section{Acknowledgements}

All authors had full access to the data and take responsibility for its integrity. All authors have read and agreed with the manuscript as written. This work was supported by National Institutes of Health grants DK56601, HL-34300 and BrickStreet Foundation Inc. We thank Jennifer Brown for her outstanding editorial assistance in the preparation of the manuscript.

\section{Author details}

'Joan C. Edwards School of Medicine, Marshall University, 1600 Medical Center Drive, Huntington, WV, 25701-3655, USA. ${ }^{2}$ Department of Drug Science, Section of Biochemistry, University of Catania, Viale Andrea Doria, 6, 95125 Catania, Italy. ${ }^{3}$ Department of Physiology and Pharmacology, University of Toledo, 3000 Arlington Avenue, Toledo, OH, 43614-2598, USA. ${ }^{4}$ Department of Medicine, New York Medical College, Munger Pavilion, Valhalla, NY, 10595, USA. ${ }^{5}$ Brooklyn Fertility Center, Columbia University, 55 Central Park West, New York, NY 10023, USA.

Received: 10 August 2012 Revised: 7 December 2012 Accepted: 21 January 2013 Published: 12 March 2013

\section{References}

1. Mandrup S, Lane MD: Regulating adipogenesis. J Biol Chem 1997, 272:5367-5370.

2. Billon N, Monteiro MC, Dani C: Developmental origin of adipocytes: new insights into a pending question. Biol Cell 2008, 100:563-575.

3. Wislet-Gendebien S, Wautier F, Leprince P, Rogister B: Astrocytic and neuronal fate of mesenchymal stem cells expressing nestin. Brain Res Bull 2005, 68:95-102.

4. Ailhaud G: Adipose tissue as a secretory organ: from adipogenesis to the metabolic syndrome. C R Biol 2006, 329:570-577.

5. Gesta S, Tseng YH, Kahn CR: Developmental origin of fat: tracking obesity to its source. Cell 2007, 131:242-256.

6. Puri N, Sodhi K, Haarstad M, Kim DH, Bohinc S, Foglio E, Favero G, Abraham NG: Heme induced oxidative stress attenuates sirtuin 1 and enhances adipogenesis in mesenchymal stem cells and mouse preadipocytes. J Cell Biochem 2012, 113:1926-1935.

7. Vestergaard P: Bone metabolism in type 2 diabetes and role of thiazolidinediones. Curr Opin Endocrinol Diabetes Obes 2009, 16:125-131.

8. James AW, Leucht P, Levi B, Carre AL, Xu Y, Helms JA, Longaker MT: Sonic Hedgehog influences the balance of osteogenesis and adipogenesis in mouse adipose-derived stromal cells. Tissue Eng Part A 2010, 16:2605-2616.

9. Clevers $\mathrm{H}$ : Wnt/beta-catenin signaling in development and disease. Cell 2006, 127:469-480

10. Cadigan KM, Liu YI: Wnt signaling: complexity at the surface. J Cell Sci 2006, 119:395-402

11. Bennett CN, Ross SE, Longo KA, Bajnok L, Hemati N, Johnson KW, Harrison SD, MacDougald OA: Regulation of Wnt signaling during adipogenesis. J Biol Chem 2002, 277:30998-31004.

12. MacDonald BT, Tamai $K$, He X: Wnt/beta-catenin signaling: components, mechanisms, and diseases. Dev Cell 2009, 17:9-26.

13. Longo KA, Wright WS, Kang S, Gerin I, Chiang SH, Lucas PC, Opp MR, MacDougald OA: Wnt10b inhibits development of white and brown adipose tissues. J Biol Chem 2004, 279:35503-35509.

14. Prestwich TC, MacDougald OA: Wnt/beta-catenin signaling in adipogenesis and metabolism. Curr Opin Cell Biol 2007, 19:612-617.

15. Kawai M, Mushiake S, Bessho K, Murakami M, Namba N, Kokubu C, Michigami T, Ozono K: Wnt/Lrp/beta-catenin signaling suppresses adipogenesis by inhibiting mutual activation of PPARgamma and C/ EBPalpha. Biochem Biophys Res Commun 2007, 363:276-282.

16. Ross SE, Hemati N, Longo KA, Bennett CN, Lucas PC, Erickson RL, MacDougald OA: Inhibition of adipogenesis by Wnt signaling. Science 2000, 289:950-953.

17. Okamura M, Kudo H, Wakabayashi K, Tanaka T, Nonaka A, Uchida A, Tsutsumi S, Sakakibara I, Naito M, Osborne TF, Hamakubo T, Ito S, Aburatani H, Yanagisawa M, Kodama T, Sakai J: COUP-TFIl acts downstream of Wnt/beta-catenin signal to silence PPARgamma gene expression and repress adipogenesis. Proc Natl Acad Sci USA 2009, 106:5819-5824.
18. Rosen ED, MacDougald OA: Adipocyte differentiation from the inside out. Nat Rev Mol Cell Biol 2006, 7:885-896.

19. Wang Y, Kim KA, Kim JH, Sul HS: Pref-1, a preadipocyte secreted factor that inhibits adipogenesis. J Nutr 2006, 136:2953-2956.

20. Smas CM, Sul HS: Pref-1, a protein containing EGF-like repeats, inhibits adipocyte differentiation. Cell 1993, 73:725-734.

21. Kamei Y, Suganami T, Kohda T, Ishino F, Yasuda K, Miura S, Ezaki O, Ogawa Y: Peg1/Mest in obese adipose tissue is expressed from the paternal allele in an isoform-specific manner. FEBS Lett 2007, 581:91-96.

22. Takahashi M, Kamei Y, Ezaki O: Mest/Peg1 imprinted gene enlarges adipocytes and is a marker of adipocyte size. Am J Physiol Endocrinol Metab 2005, 288:E117-E124.

23. Peterson SJ, Drummond G, Kim DH, Li M, Kruger AL, Ikehara S, Abraham NG: L-4F treatment reduces adiposity, increases adiponectin levels and improves insulin sensitivity in obese mice. J Lipid Res 2008, 49:1658-1669.

24. Peterson SJ, Kim DH, Li M, Positano V, Vanella L, Rodella LF, Piccolomini F, Puri N, Gastaldelli A, Kusmic C, L'Abbate A, Abraham NG: The L-4F mimetic peptide prevents insulin resistance through increased levels of HO-1, pAMPK, and pAKT in obese mice. J Lipid Res 2009, 50:1293-1304

25. Li M, Kim DH, Tsenovoy PL, Peterson SJ, Rezzani R, Rodella LF, Aronow WS, Ikehara S, Abraham NG: Treatment of obese diabetic mice with a heme oxygenase inducer reduces visceral and subcutaneous adiposity, increases adiponectin levels, and improves insulin sensitivity and glucose tolerance. Diabetes 2008, 57:1526-1535.

26. Vanella L, Kim DH, Asprinio D, Peterson SJ, Barbagallo I, Vanella A, Goldstein D, Ikehara S, Kappas A, Abraham NG: HO-1 expression increases mesenchymal stem cell-derived osteoblasts but decreases adipocyte lineage. Bone 2010, 46:236-243.

27. Neumann CJ: Hedgehogs as negative regulators of the cell cycle. Cell Cycle 2005, 4:1139-1140.

28. Fontaine C, Cousin W, Plaisant M, Dani C, Peraldi P: Hedgehog signaling alters adipocyte maturation of human mesenchymal stem cells. Stem Cells 2008, 26:1037-1046.

29. Chhikara M, Wang S, Kern SJ, Ferreyra GA, Barb JJ, Munson PJ, Danner RL: Carbon monoxide blocks lipopolysaccharide-induced gene expression by interfering with proximal TLR4 to NF-kappaB signal transduction in human monocytes. PLoS One 2009, 4:e8139.

30. Abraham NG: Molecular regulation-biological role of heme in hematopoiesis. Blood Rev 1991, 5:19-28.

31. Abraham NG, Kappas A: Pharmacological and clinical aspects of heme oxygenase. Pharmacol Rev 2008, 60:79-127.

32. Li M, Peterson S, Husney D, Inaba M, Guo K, Kappas A, Ikehara S, Abraham NG: Long-lasting expression of HO-1 delays progression of type I diabetes in NOD mice. Cell Cycle 2007, 6:567-571.

33. Berg AH, Scherer PE: Adipose tissue, inflammation, and cardiovascular disease. Circ Res 2005, 96:939-949.

34. Kim DH, Burgess AP, Li M, Tsenovoy PL, Addabbo F, McClung JA, Puri N, Abraham NG: Heme oxygenase-mediated increases in adiponectin decrease fat content and inflammatory cytokines, tumor necrosis factoralpha and interleukin- 6 in Zucker rats and reduce adipogenesis in human mesenchymal stem cells. J Pharmacol Exp Ther 2008, 325:833-840.

35. Vanella L, Kim DH, Sodhi K, Barbagallo I, Burgess AP, Falck JR, Schwartzman ML, Abraham NG: Crosstalk between EET and HO-1 downregulates Bach1 and adipogenic marker expression in mesenchymal stem cell derived adipocytes. Prostaglandins Other Lipid Mediat 2011, 96:54-62.

36. Kim DH, Vanella L, Inoue K, Burgess A, Gotlinger K, Manthati VL, Koduru SR, Zeldin DC, Falck JR, Schwartzman ML, Abraham NG: Epoxyeicosatrienoic acid agonist regulates human mesenchymal stem cell-derived adipocytes through activation of HO-1-pAKT signaling and a decrease in PPARgamma. Stem Cells Dev 2010, 19:1863-1873.

37. Kim DH, Vanella L, Inoue K, Burgess A, Gotlinger K, Manthati VL, Koduru SR, Zeldin DC, Falck JR, Schwartzman ML, Abraham NG: EET-Agonist Regulates Human Mesenchymal Stem Cells-Derived Adipocytes Through Activation of HO-1-pAKT Signaling and a decrease in PPARgamma. Stem Cells Dev 2010, 19:1863-1873.

38. Chertkov JL, Jiang S, Lutton JD, Levere RD, Abraham NG: Hemin stimulation of hemopoiesis in murine long-term bone marrow culture. Exp Hematol 1991, 19:905-909. 
39. Tavian D, Colombo R: Improved cytochemical method for detecting Jordans' bodies in neutral lipid storage diseases. J Clin Pathol 2007, 60:956-958

40. Sambuceti G, Morbelli S, Vanella L, Kusmic C, Marini C, Massollo M, Augeri C, Corselli M, Ghersi C, Chiavarina B, Rodella LF, L'Abbate A, Drummond G, Abraham NG, Frassoni F: Diabetes impairs the vascular recruitment of normal stem cells by oxidant damage; reversed by increases in PAMPK, heme oxygenase-1 and adiponectin. Stem Cells 2009, 27:399-407.

41. Sodhi K, Inoue K, Gotlinger K, Canestraro M, Vanella L, Kim DH, Manthati VL, Koduru SR, Falck JR, Schwartzman ML, Abraham NG: Epoxyeicosatrienoic acid agonist rescues the metabolic syndrome phenotype of HO-2-null mice. J Pharmacol Exp Ther 2009, 331:906-916.

42. Lowe CE, O'Rahilly S, Rochford JJ: Adipogenesis at a glance. J Cell Sci 2011, 124:2681-2686.

43. Gummersbach C, Hemmrich K, Kroncke KD, Suschek CV, Fehsel K, Pallua N: New aspects of adipogenesis: radicals and oxidative stress. Differentiation 2009, 77:115-120.

44. Puri N, Zhang F, Monu SR, Sodhi K, Bellner L, Lamon BD, Zhang Y, Abraham NG, Nasjletti A: Antioxidants Condition pleiotropic vascular responses to exogenous $\mathrm{H}(2) \mathrm{O}(2)$ : role of modulation of vascular TP Receptors and the heme oxygenase system. Antioxid Redox Signal 2012, 18:471-480.

45. Pohl J, Ring A, Korkmaz U, Ehehalt R, Stremmel W: FAT/CD36-mediated long-chain fatty acid uptake in adipocytes requires plasma membrane rafts. Mol Biol Cell 2005, 16:24-31.

46. Modder UI, Oursler MJ, Khosla S, Monroe DG: Wnt10b activates the Wnt, notch, and NFkappaB pathways in U2OS osteosarcoma cells. J Cell Biochem 2011, 112:1392-1402.

47. Christodoulides C, Laudes M, Cawthorn WP, Schinner S, Soos M, O'Rahilly S, Sethi JK, Vidal-Puig A: The Wnt antagonist Dickkopf-1 and its receptors are coordinately regulated during early human adipogenesis. J Cell Sci 2006, 119:2613-2620.

48. Nicolai A, Li M, Kim DH, Peterson SJ, Vanella L, Positano V, Gastaldelli A, Rezzani R, Rodella LF, Drummond G, Kusmic C, L'Abbate A, Kappas A, Abraham NG: Heme Oxygenase-1 Induction Remodels Adipose Tissue and Improves Insulin Sensitivity in Obesity-Induced Diabetic Rats. Hypertension 2009, 53:508-515.

49. Sodhi K, Puri N, Inoue K, Falck JR, Schwartzman ML, Abraham NG: EET agonist prevents adiposity and vascular dysfunction in rats fed a high fat diet via a decrease in Bach 1 and an increase in HO-1 levels. Prostaglandins Other Lipid Mediat 2011, 98:133-142.

50. Logan CY, Nusse R: The Wnt signaling pathway in development and disease. Annu Rev Cell Dev Biol 2004, 20:781-810.

51. Taipale J, Beachy PA: The Hedgehog and Wnt signalling pathways in cancer. Nature 2001, 411:349-354

52. Vertino AM, Taylor-Jones JM, Longo KA, Bearden ED, Lane TF, McGehee RE $\mathrm{Jr}$, MacDougald OA, Peterson CA: Wnt10b deficiency promotes coexpression of myogenic and adipogenic programs in myoblasts. Mol Biol Cell 2005, 16:2039-2048.

53. Zhang Y, Sun Y, Wang F, Wang Z, Peng Y, Li R: Downregulating the canonical Wnt/beta-catenin signaling pathway attenuates the susceptibility to autism-like phenotypes by decreasing oxidative stress. Neurochem Res 2012, 37:1409-1419.

54. Sul HS: Minireview: Pref-1: role in adipogenesis and mesenchymal cell fate. Mol Endocrinol 2009, 23:1717-1725.

55. Lee J, Jung E, Lee J, Kim S, Huh S, Kim Y, Kim Y, Byun SY, Kim YS, Park D: Isorhamnetin represses adipogenesis in 3T3-L1 cells. Obesity (Silver Spring) 2009, 17:226-232.

56. Koza RA, Nikonova L, Hogan J, Rim JS, Mendoza T, Faulk C, Skaf J, Kozak LP: Changes in gene expression foreshadow diet-induced obesity in genetically identical mice. PLoS Genet 2006, 2:e81.

\section{doi:10.1186/scrt176}

Cite this article as: Vanella et al:: Increased heme-oxygenase 1 expression in mesenchymal stem cell-derived adipocytes decreases differentiation and lipid accumulation via upregulation of the canonical Wnt signaling cascade. Stem Cell Research \& Therapy 2013 4:28.

\section{Submit your next manuscript to BioMed Central and take full advantage of:}

- Convenient online submission

- Thorough peer review

- No space constraints or color figure charges

- Immediate publication on acceptance

- Inclusion in PubMed, CAS, Scopus and Google Scholar

- Research which is freely available for redistribution 